Article

\title{
Annual Changes in Seasonal River Water Temperatures in the Eastern and Western United States
}

\author{
Tyler Wagner ${ }^{1, *}$, Stephen R. Midway ${ }^{2}$, Joanna B. Whittier ${ }^{3}$, Jefferson T. DeWeber ${ }^{4}$ and \\ Craig P. Paukert 5 \\ 1 U.S. Geological Survey, Pennsylvania Cooperative Fish and Wildlife Research Unit, \\ The Pennsylvania State University, 402 Forest Resources Building, University Park, PA 16802, USA \\ 22257 Energy, Coast, and Environment Building, Department of Oceanography and Coastal Science, \\ Louisiana State University, Baton Rouge, LA 70803, USA; smidway@lsu.edu \\ 3302 Anheuser-Busch Natural Resources Building, Department of Fisheries and Wildlife Sciences, \\ University of Missouri, Columbia, MO 65211, USA; whittierj@missouri.edu \\ 4546 Nash Hall, Department of Fisheries and Wildlife, Oregon State University, Corvallis, OR 97331, USA; \\ jtdeweber@gmail.com \\ 5 U.S. Geological Survey, Missouri Cooperative Fish and Wildlife Research Unit, \\ 302 Anheuser-Busch Natural Resources Building, Department of Fisheries and Wildlife Sciences, \\ University of Missouri, Columbia, MO 65211, USA; paukertc@missouri.edu \\ * Correspondence: txw19@psu.edu; Tel.: +1-814-865-6592
}

Academic Editors: James H. Cowan, Jr. and Arjen Y. Hoekstra

Received: 3 October 2016; Accepted: 2 February 2017; Published: 4 February 2017

\begin{abstract}
Changes in river water temperatures are anticipated to have direct effects on thermal habitat and fish population vital rates, and therefore, understanding temporal trends in water temperatures may be necessary for predicting changes in thermal habitat and how species might respond to such changes. However, many investigations into trends in water temperatures use regression methods that assume long-term monotonic changes in temperature, when in fact changes are likely to be nonmonotonic. Therefore, our objective was to highlight the need and provide an example of an analytical method to better quantify the short-term, nonmonotonic temporal changes in thermal habitat that are likely necessary to determine the effects of changing thermal conditions on fish populations and communities. To achieve this objective, this study uses Bayesian dynamic linear models (DLMs) to examine seasonal trends in river water temperatures from sites located in the eastern and western United States, regions that have dramatically different riverine habitats and fish communities. We estimated the annual rate of change in water temperature and found little evidence of seasonal changes in water temperatures in the eastern U.S. We found more evidence of warming for river sites located in the western U.S., particularly during the fall and winter seasons. Use of DLMs provided a more detailed view of temporal dynamics in river thermal habitat compared to more traditional methods by quantifying year-to-year changes and associated uncertainty, providing managers with the information needed to adapt decision making to short-term changes in habitat conditions that may be necessary for conserving aquatic resources in the face of a changing climate.
\end{abstract}

Keywords: trends; river water temperature; Bayesian estimation; dynamic linear models

\section{Introduction}

Water temperature is considered the "master variable" of fish habitat, affecting stream metabolism, fish bioenergetics and structuring fish communities and the ecosystem services they support [1-3]. Changes in river water temperatures, and therefore thermal habitat, are projected to have particularly 
important effects on many freshwater communities. Predicted and recently-observed effects of increasing water temperature on riverine fish species include range shifts towards upstream, higher elevations [4], influences on migration timing [5,6] and changes in community structure [7]. In addition, because temperature is a key controller of physiological processes, changes in water temperatures have the potential to affect population vital rates, including growth and reproduction [8-10]. These effects not only have implications for habitats and the aquatic communities they support, but are projected to have substantial economic impacts due to the loss of recreational fisheries [11].

Given that water temperature is a fundamental property of fish habitat that will likely be affected by a changing climate, it is important to quantify trends in water temperature in order to assess current thermal habitat status, project future conditions and prioritize areas for protection [12]. For many riverine fish species, this implies quantifying trends in seasonal water temperatures, specifically seasons that correspond to periods of potential thermal stress (e.g., summer months) or that correspond to important life history events, such as spawning [13]. For example, Isaak et al. [14] examined trends in seasonal (spring, summer, fall and winter) river water temperatures, each of which may be important in influencing particular life history events of stream-dwelling cold water fishes.

Several studies have examined temporal trends in river water temperatures (e.g., [14-18]), and although a direct comparison of findings among studies is not always possible, it is evident from these previous investigations that there is variability in how the thermal habitat of rivers change over time and how they may be responding to drivers of water temperature, such as changes in climate. For example, Kaushal et al. [15] found that 50\% (20 out of 40) of the U.S. river sites they examined showed statistically significant long-term linear warming trends in annual mean temperature, and Rice and Jastram [18] found substantial variability in the direction and magnitude of trends in river water temperature from the mid-Atlantic region, USA. It is likely that local landscape characteristics, both natural (e.g., watershed area) and anthropogenic (e.g., land use and the presence of dams), are responsible for at least some of the observed variability in how rivers respond to climate change [14,18]. In addition, anthropogenic land use changes and other activities can also alter water temperature and affect the spatial and temporal distribution of thermally-suitable habitat directly. However, some of the difficulties in making inferences about temporal trends are due to some studies attempting to detect monotonic trends, an assumption that is likely not reasonable for river water temperature data [17]. In addition, the statistical models often fitted to a time series dataset to detect monotonic trends (e.g., linear regression) are sensitive to the length of the time series analyzed, with the statistical power of detecting a trend a function of sample size. Thus, null hypothesis testing, combined with statistical models that assume long-term monotonic trends, may obscure the ability to make inferences about ecologically-significant changes in thermal habitat. In addition, inferences from these approaches are limited to long-term average changes because the coefficients of the models are static, prohibiting inferences about whether or not more recent temporal dynamics deviate from historical dynamics. Understanding these recent dynamics may be important in the context of understanding short-term responses of fish populations to changes in thermal habitat and for informing management decisions within a management-relevant time frame.

Therefore, our objective was to highlight the need and provide an example of an analytical method to better quantify the short-term, nonmonotonic temporal changes in thermal habitat that are likely necessary to determine the effects of changing thermal conditions on fish populations and communities. Our intent was to highlight the use of a specific analytical method for making inferences about nonmonotonic trends in thermal habitat by analyzing time series of water temperatures from rivers in two distinctly different areas of the U.S., and not to provide an exhaustive comparison of potential models that could be used to make inferences about changes in thermal habitat. This study uses Bayesian dynamic linear models (DLMs) to examine seasonal trends in river water temperatures from the eastern and western U.S. that may be due to factors, such as climate change, given observed increases in air temperature (e.g., [18]). Specifically, we estimated the annual rate of change in water temperature and calculated the probability of annual increases in water temperature occurring. 
Based on previous research (e.g., [14,15]), we predicted that we would observe evidence of increasing river water temperatures in response to climate change, particularly in the summer months. We suggest that the combination of methods such as DLMs and Bayesian estimation provides a powerful approach for evaluating the temporal dynamics of river water temperature within the context of fish habitat and population management in the face of a changing climate. Even if monotonic changes are predicted, understanding the temporal dynamics (i.e., year-to-year changes) in temperature could be important for making predictions about the potential effects of climate change on rivers and the biological communities they support.

\section{Materials and Methods}

\subsection{Study Area}

The study regions included two regions of the U.S., a portion of the eastern U.S. and the western U.S., the Upper Colorado River Basin (UCRB; Figure 1). The study area in the eastern U.S. included the native range of the eastern brook trout Salvelinus fontinalis as defined by the Eastern Brook Trout Joint Venture [19]. See DeWeber and Wagner [20] for the details. This region was selected because the eastern brook trout is a cold water species of concern throughout much of its native range and one that has received considerable research and management attention within the context of the potential effects of climate change on suitable thermal habitat $[19,21]$. The UCRB was selected because it differs in climate, physiography and land use compared to the eastern U.S., and therefore, changes in the drivers of thermal habitat, such as climate change, may differ in these two regions. In addition, fishes of the UCRB have one of the highest levels of endemism in the U.S. with many being endangered [22]. Therefore, quantifying temporal dynamics in thermal habitat in these systems is of importance for the conservation and management of these unique ecosystems.

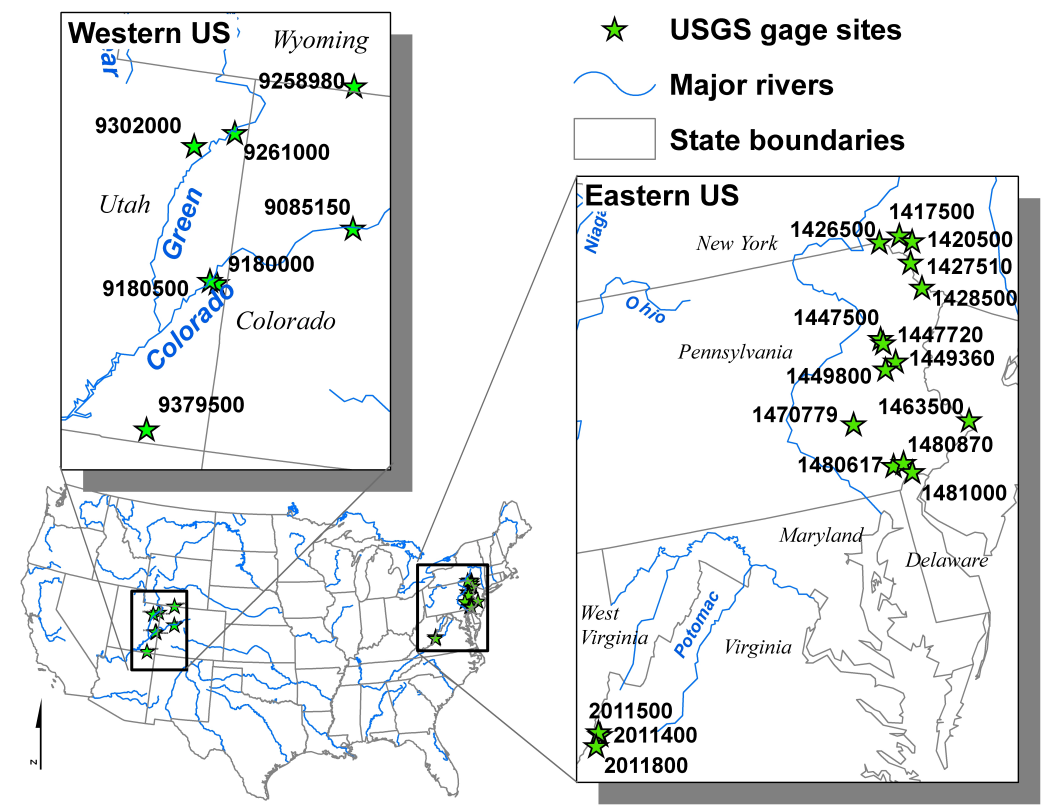

Figure 1. Study map showing U.S. Geological Survey river water temperature gauge locations for both the eastern and western (Upper Colorado River Basin) U.S. Numerical codes corresponds to the U.S. Geological Survey gauge ID.

\subsection{River Water Temperature Data}

River water temperature data were obtained from the U.S. Geological Survey's (USGS) National Water Information System (NWIS; http://waterdata.usgs.gov/nwis). Water temperature data consisted of daily measurements of mean water temperature, which were summarized to monthly 
means values for use in the analysis. In an effort to only include sites with sufficient data and to reduce the effects of dams on water temperature observations, we screened the USGS gauges as follows. First, we only included gauges with at least nine years of data. Although there was not a minimum number of years required for our modeling approach, we decided that this length of time series would at least provide the opportunity to examine more recent temporal trends, and it allowed us to increase our sample size for sites located in the UCRB. Second, following the approach of DeWeber and Wagner [20], we excluded gauges from our analysis where the nearest upstream dam was $>100 \mathrm{ft}$ in height or within $5 \mathrm{~km}$. The decision to only examine sites with the "minimal" influence of impoundments was made in an effort to improve inferences about observed dynamics being related to climate forcing and not a function of changing water management policies that may have occurred over time. Although our analysis is focused on changes in thermal habitat in general, climate change is, and is expected to be, a dominant driver. Our approach could easily be applied to systems under more intensive water management practices to better elucidate their effects on thermal habitat. In fact, it has been suggested that examining "minimally human-influenced" sites may help in elucidating climate effects on river water temperature [16]. Although we acknowledge that we were not able to examine truly "minimally-impacted streams", attempts to reduce the effects of water management policies in impoundments is likely important [14]. After applying the screening criteria, there were 17 river sites in the eastern U.S. and seven sites in the UCRB included in the analysis (Figure 1). For sites in the eastern U.S., data were available starting in 1968-2015, and the length of the time series for each site range from 10 to 45 years. For the UCRB, data were available from 1980 to 2015, with the time series length for each site ranging from 9 to 35 years.

\subsection{Landscape and Land Use Data}

Because both the position of a river in the landscape and catchment land use can influence water temperature [20], we obtained landscape and land use information (2001 National Land Cover Data) for each gauge site from the National Hydrography Dataset Plus Version 1.0 [23] in an effort to examine correlations with estimated temporal trends. We focused on landscape predictors that are shown to be related to river water temperature [20]. Specifically, we chose elevation, catchment area and the proportion of urban land use in the catchment upstream of a site (Table 1). Although we could have chosen additional landscape predictors (e.g., other land use types), they were all correlated to some degree, so we decided to focus on a subset with well-defined mechanisms in terms of the effects on stream water temperature.

Table 1. List of study sites, including the U.S. Geological Survey gauge ID, elevation (m), catchment area $\left(\mathrm{km}^{2}\right)$ and the proportion of urban land use in the catchment upstream of study sites.

\begin{tabular}{ccccc}
\hline Gauge ID & Station Name & Elevation & Catchment Area & Urban Land Use \\
\hline 1417500 & East Branch Delaware River at Harvard, NY & 301.6 & 1185.01 & 0.003 \\
1420500 & Beaver Kill River at Cooks Falls, NY & 337.41 & 630.57 & 0.01 \\
1426500 & West Branch Delaware River at Hale Eddy, NY & 277.84 & 1537.79 & 0.03 \\
1427510 & Delaware River at Callicoon, NY & 218.65 & 4721.71 & 0.01 \\
1428500 & Delaware River at Barryville, NY & 176.63 & 5229.46 & 0.01 \\
1447500 & Lehigh River at Stoddartsville, PA & 428.07 & 220.29 & 0.05 \\
1447720 & Tobyhanna Creek near Blakeslee, PA & 458.57 & 308.38 & 0.24 \\
1449360 & Pohopoco Creek at Kresgeville, PA & 197.98 & 133.72 & 0.08 \\
1449800 & Pohopoco Creek near Parryville, PA & 149.64 & 249.51 & 0.05 \\
1463500 & Delaware River at Trenton, NJ & 0 & $17,441.1$ & 0.24 \\
1470779 & Tulpehocken Creek near Bernville, PA & 92.49 & 181.97 & 0.49 \\
1480617 & West Branch Brandywine Creek at Modena, PA & 80.53 & 118.85 & 0.96 \\
\hline
\end{tabular}


Table 1. Cont.

\begin{tabular}{ccccc}
\hline Gauge ID & Station Name & Elevation & Catchment Area & Urban Land Use \\
\hline 1480870 & East Branch Brandywine Creek at Downingtown, PA & 60.78 & 232.15 & 0.54 \\
1481000 & Brandywine Creek at Chadds Ford, PA & 46.53 & 720.55 & 0.52 \\
2011400 & Jackson River near Bacova, VA & 482.19 & 409.88 & 0 \\
2011500 & Black Creek near Mountain Grove, VA & 514.61 & 348.07 & 0.01 \\
2011800 & Jackson River, near Hot Springs, VA & 425.64 & 894.5 & 0.005 \\
9085150 & Colorado River near Glenwood Springs, CO & 1718.36 & $15,575.74$ & 0.01 \\
9180000 & Dolores River, near Cisco, UT & 1275.63 & $11,841.39$ & 0 \\
9180500 & Colorado River near Cisco, UT & 1243.54 & $61,791.09$ & 0.02 \\
9258980 & Muddy Creek near Baggs, WY & 1903.2 & 2474.79 & 0 \\
9261000 & Green River near Jensen, UT & 1452 & 65,137 & 0.18 \\
9302000 & Duchesne River near Randlett, UT & 1447.16 & 9741.67 & 0 \\
9379500 & San Juan River near Bluff, UT & 1214.84 & $58,155.8$ & 0 \\
\hline
\end{tabular}

\subsection{Statistical Modeling: Trend Estimation}

Bayesian DLMs were used to examine seasonal temporal trends in river water temperature. DLMs allows for time-varying parameters that are most strongly influenced by the current year's information and data from other years closest in time, as opposed to traditional linear regression where the parameters (i.e., slope and intercept) are influenced directly by all observations [24,25]. In addition, DLMs easily accommodate missing and unequally-spaced data, which can be common for temperature time series data, and the way the model is parameterized allows for the incorporation of both intra-seasonal and interannual variation when assessing seasonal temporal trends. Lastly, inferences about trends are not as dependent on the length of the time series for detecting "significant" trends using null hypothesis testing. The DLM was parameterized as follows:

Observation equation:

$$
y_{t i}=\text { level }_{t}+\psi_{t i}, \psi_{t i} \sim N\left(0, \Psi_{t}\right)
$$

Systems equations:

$$
\begin{gathered}
\text { level }_{t}=\text { level }_{t-1}+\text { rate }_{t}+\omega_{t 1}, \omega_{t 1} \sim N\left(0, \Omega_{t 1}\right) \\
\text { rate }_{t}=\text { rate }_{t-1}+\omega_{t 2}, \omega_{t 2} \sim N\left(0, \Omega_{t 2}\right)
\end{gathered}
$$

where $y_{t i}$ is seasonal river temperature observation $i$ in year $t$; level $l_{t}$ is the mean seasonal temperature at time $t$; rate $_{t}$ is the expected rate of change of temperature (i.e., the slope between consecutive years); and $\psi_{t i}$ and $\omega_{t j}(j=1,2)$ are the error terms for year $t$, which are distributed as $N\left(0, \Psi_{t}\right)$ and $N\left(0, \Omega_{t j}\right)$. Diffuse priors are used for all parameters. See Wagner et al. [26] for details related to prior specification. All models were fitted using Bayesian estimation using JAGS in the rjags package [27], run from within $\mathrm{R}$ [28]. Three parallel Markov chains were run, beginning each with a different value. From a total of 70,000 samples from the posterior distribution, the first 10,000 samples of each chain were discarded, then we retained every third sample for a total of 60,000 samples used to characterize the posterior distributions. A separate DLM was fitted to each gauge's time series and for each season. We used climatological (and meteorological) definitions of seasons: spring = March, April, May; summer = June, July, August; fall = September, October, November; and winter = December, January, February. We also calculated the annual probabilities of increasing water temperatures as a way to present the results as an easily communicated metric. Annual probabilities could easily be summarized in different ways; for example, as the probability of exceeding a given species' thermal tolerance or being higher or lower than any other temperature value was deemed important by managers.

\subsection{Statistical Modeling: Land Use Correlations}

Regression trees were used to investigate potential relationships between river gauge landscape predictors and the average annual rate of change for each gauge's time series [29]. Although the DLMs estimate annual rates of change in water temperature, landscape data do not exist at an annual time 
step that would allow for relating predictors to rates of change at this temporal resolution. In addition, landscape characteristics would either change very little on an annual time-step (e.g., proportion of urban land use in a catchment) or are static (e.g., catchment area). As such, we used the average annual rate of change as the response variable because it summarized long-term temporal dynamics in water temperature for each site (i.e., was a site increasing or decreasing in water temperature, on average, over the length of the time series). We fitted regression tree models for each gauge and season separately using the $\mathrm{R}$ package rpart [30]. To prevent overfitting, trees were pruned using 10-fold cross-validation.

\section{Results}

\subsection{Temporal Trends}

Temporal dynamics in water temperatures for rivers located in the eastern U.S. were variable across space (sites) and over time, with no consistent temporal patterns among sites. Several ( $\sim 9)$ sites, however, had decreasing trends in winter water temperatures over the past approximately 10 years (Figures 2 and 3), during which time annual probabilities of increasing river water temperatures were $<0.5$ (Figure 4). Annual changes in winter river water temperature ranged from -0.59 to $0.20{ }^{\circ} \mathrm{C}$ $\left(\right.$ mean $=-0.002{ }^{\circ} \mathrm{C}$; median $\left.=0.01{ }^{\circ} \mathrm{C}\right)$. Annual changes in river water temperature during the summer season ranged from -1.03 to $0.244^{\circ} \mathrm{C}$ (mean $=-0.03{ }^{\circ} \mathrm{C}$; median $\left.=-0.02{ }^{\circ} \mathrm{C}\right)$, and these changes were relatively uncertain (see the Supplementary Materials). Accordingly, most sites in the eastern U.S. did not demonstrate a consistent increase or decrease in water temperature during the summer months, with annual probabilities of increases in water temperature varying over time (see the Supplementary Materials). Two sites (Gauge IDs 2011500 and 1463500) did demonstrate a probability $>0.5$ of an annual increase in water temperature over the most recent portion of their time series, suggesting a recent warming trend in summer river water temperatures. A similar lack of consistent seasonal trends in water temperature was observed for the spring and fall seasons (see the Supplementary Materials).
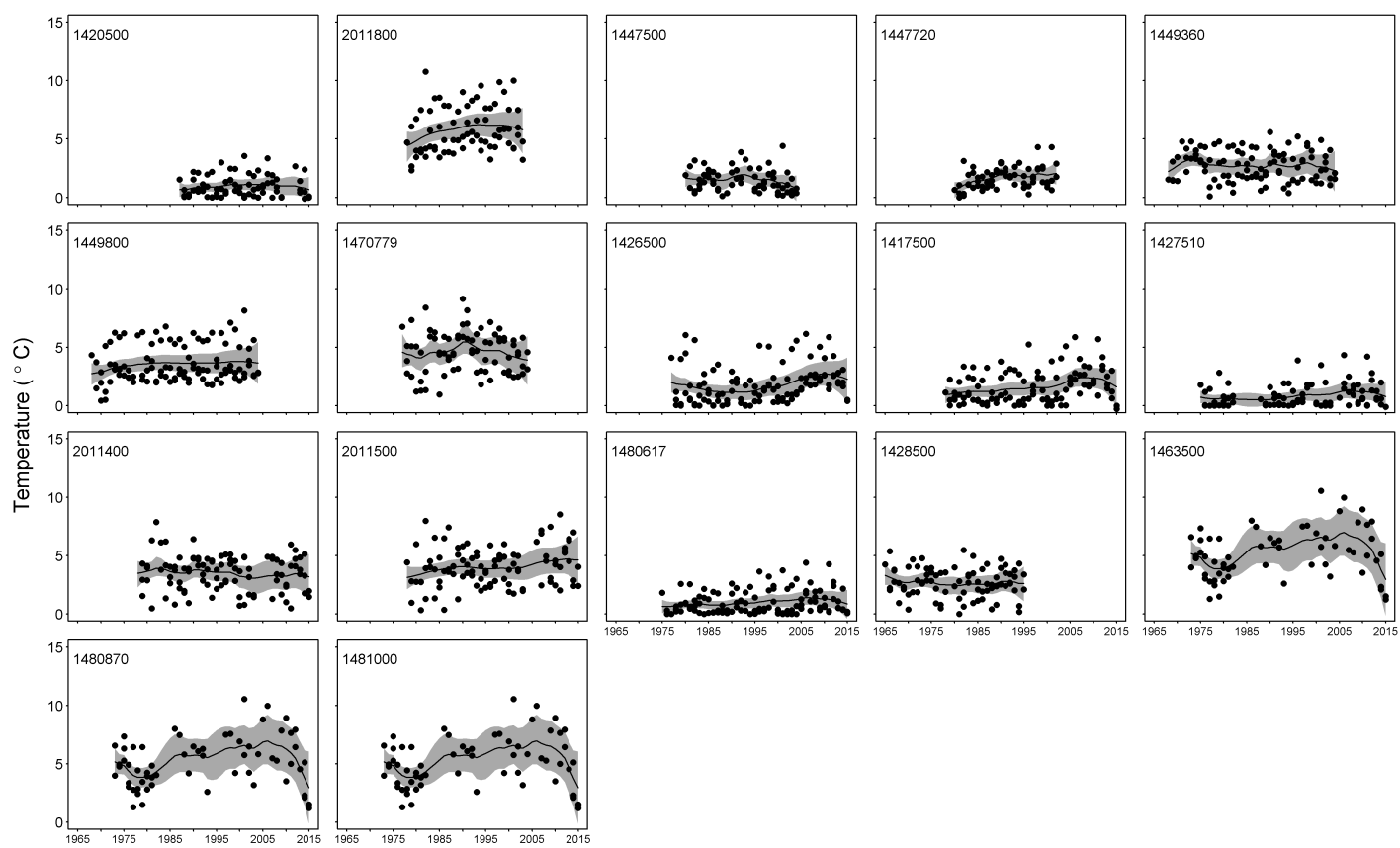

Year

Figure 2. Temporal trends in winter river water temperature for sites located in the eastern U.S. (see Figure 1 for the site map). Solid circles are observed data; solid lines are posterior mean fitted lines; and shaded areas are $95 \%$ credible regions. Numerical codes on each panel correspond to the U.S. Geological Survey gauge ID. 

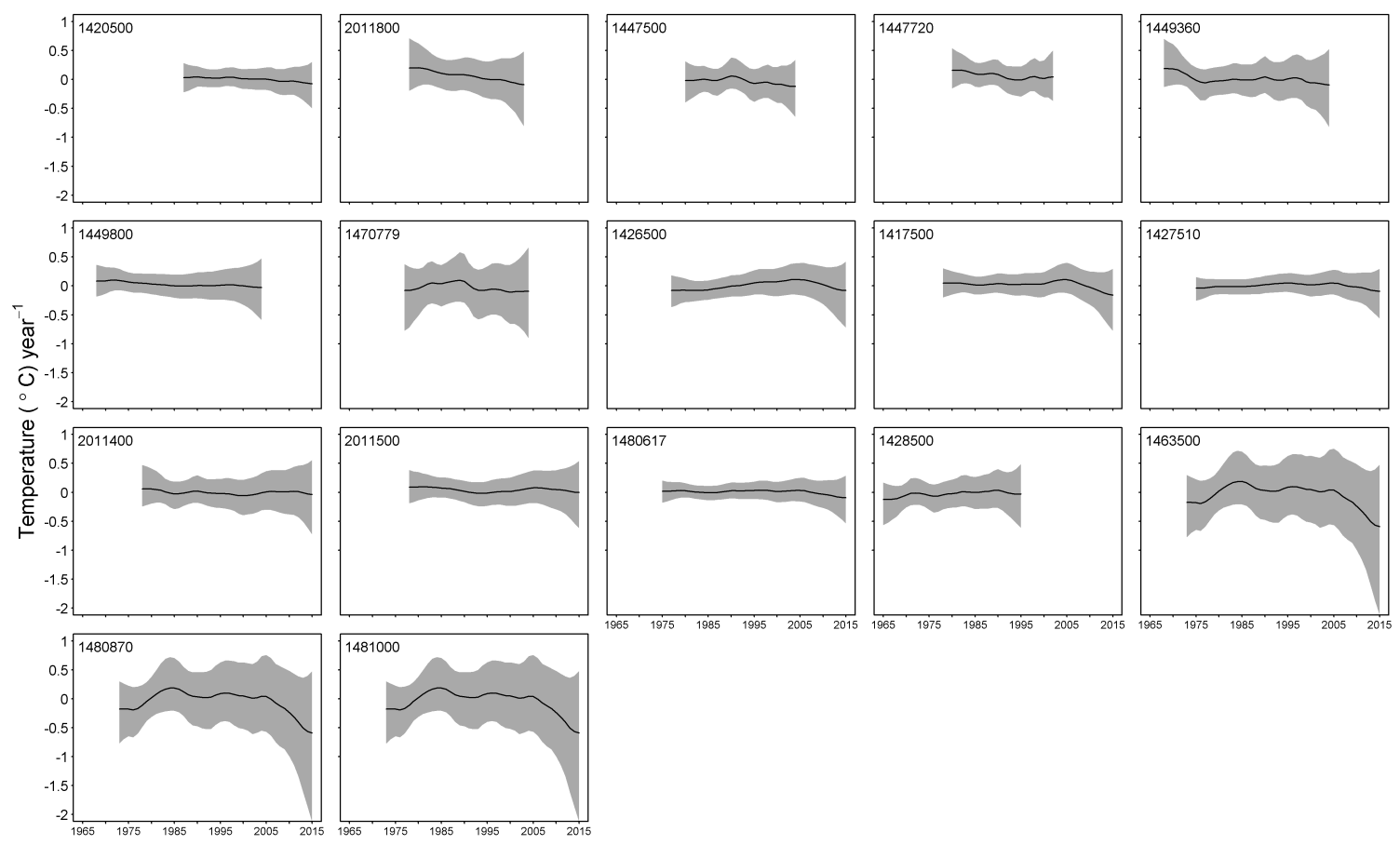

Year

Figure 3. Annual rates of change in winter river water temperature for sites located in the eastern U.S. (see Figure 1 for the site map). Solid lines are posterior means, and shaded areas are $95 \%$ credible regions. Numerical codes on each panel correspond to the U.S. Geological Survey gauge ID.
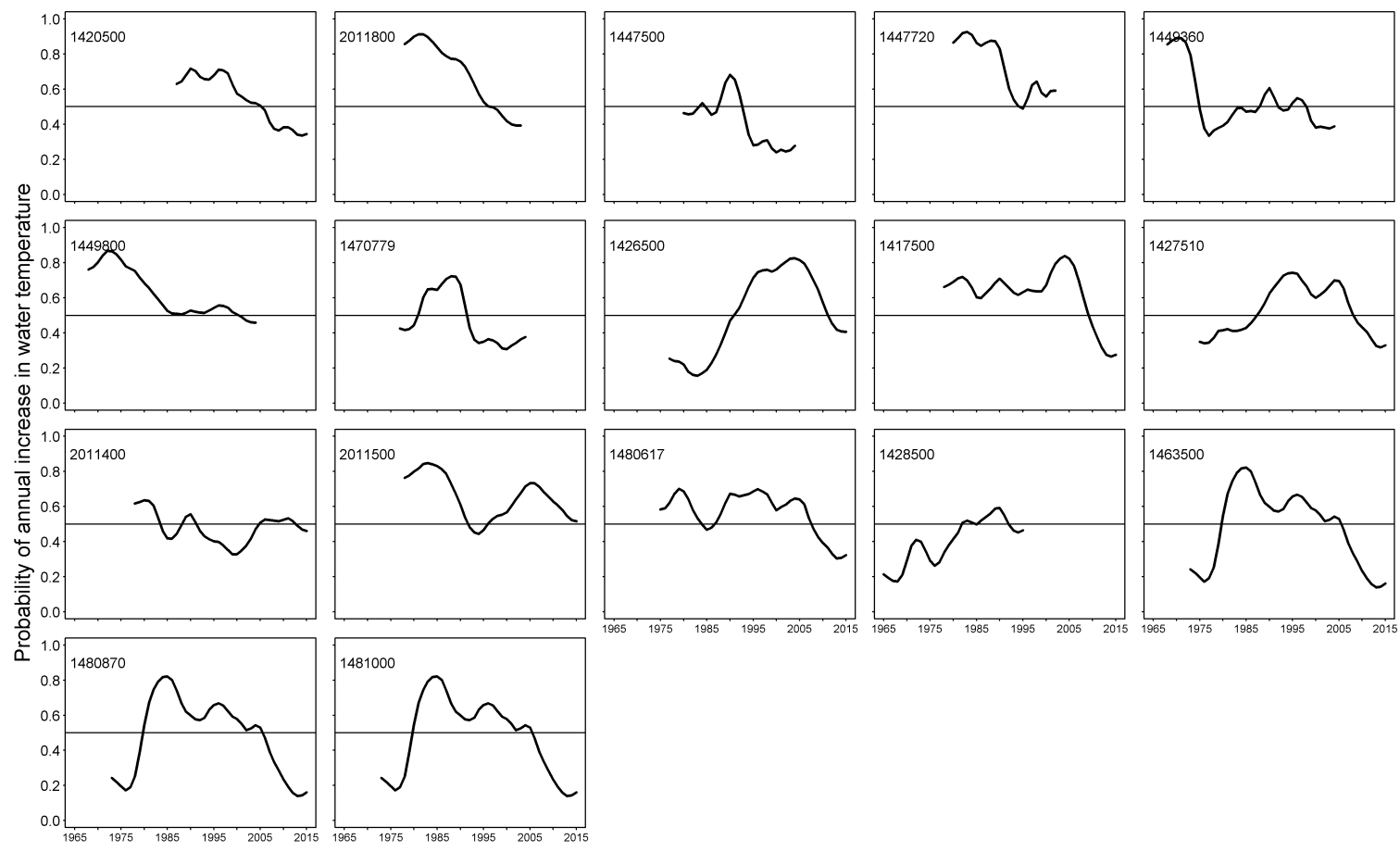

Year

Figure 4. Annual probabilities of an increase in winter river water temperature for sites located in the eastern U.S. (see Figure 1 for site map). Numerical codes on each panel correspond to the U.S. Geological Survey gauge ID. 
In contrast to the eastern U.S. rivers, there was a larger proportion of sites located in the UCRB that demonstrated increasing water temperatures in the winter (six out of six (one site did not have data for the winter season)) and fall (six out of seven sites) seasons (Figures 5 and 6; see the Supplementary Materials). For example, the probabilities of annual increases in water temperature were $>0.5$ for the entire time series or more recent years for winter and fall (Figure 7; see the Supplementary Materials). These patterns provide some evidence for recent warming of river water temperatures during these seasons. Effect sizes for annual changes in river water temperatures ranged from -0.28 to $0.38{ }^{\circ} \mathrm{C}$ (mean $=0.03{ }^{\circ} \mathrm{C}$; median $=0.02{ }^{\circ} \mathrm{C}$ ) for winter and from -0.06 to $0.22{ }^{\circ} \mathrm{C}$ (mean $=0.07^{\circ} \mathrm{C}$; median $=0.07^{\circ} \mathrm{C}$ ) for fall. Compared to the eastern U.S. sites, UCRB had a larger proportion of sites $(4 / 7)$ that had probabilities of annual increases in summer river water temperature $>0.5$ for the more recent years or entire time series (annual changes in water temperature ranged from -0.46 to $0.42{ }^{\circ} \mathrm{C}$, mean $=0.02{ }^{\circ} \mathrm{C}$, median $=0.04{ }^{\circ} \mathrm{C}$; see the Supplementary Materials). There were no apparent consistent patterns for temporal trends in spring water temperatures (see the Supplementary Materials).
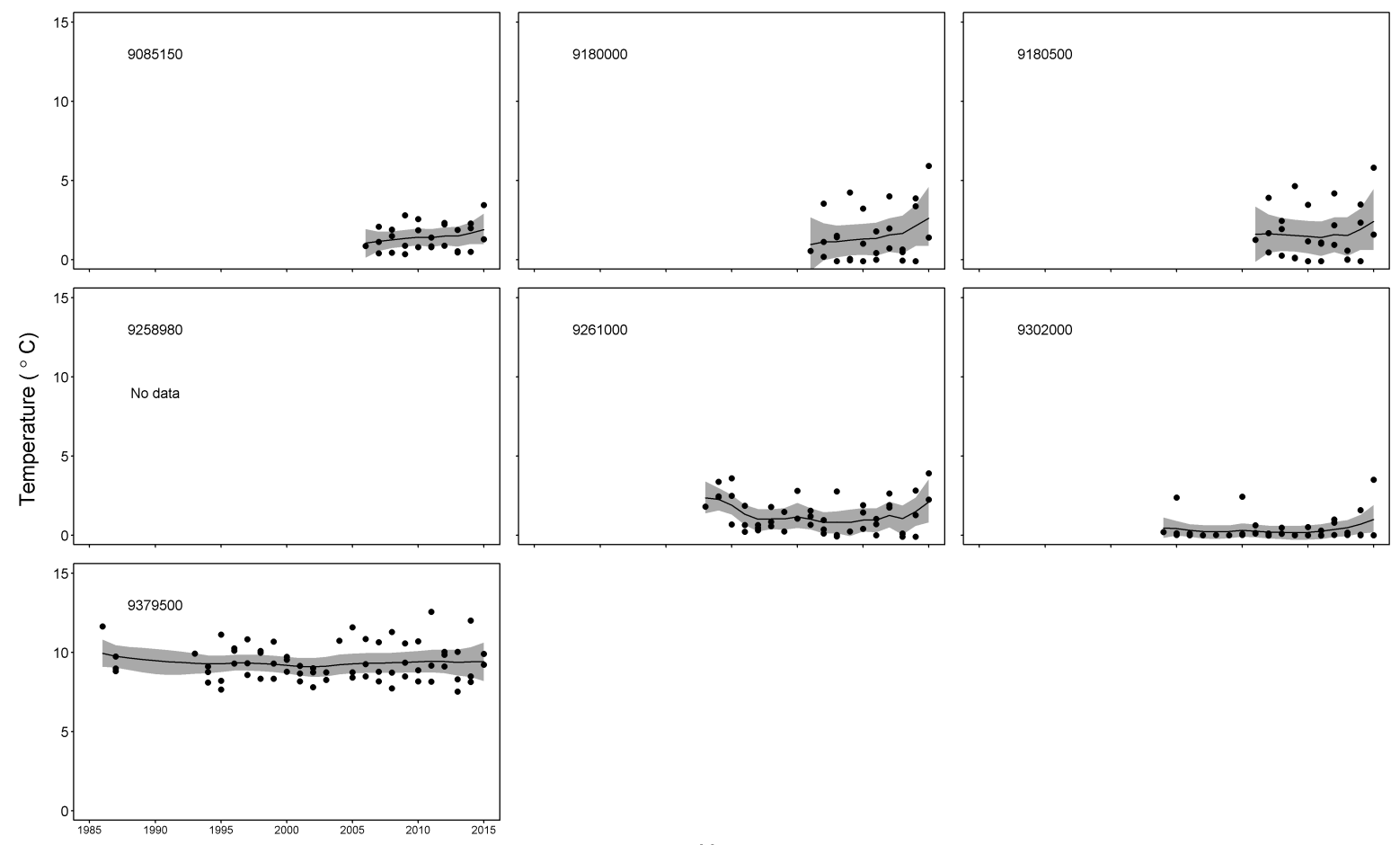

Year

Figure 5. Temporal trends in winter river water temperature for sites located in the Upper Colorado River Basin (see Figure 1 for the site map). Solid circles are observed data; solid lines are posterior mean fitted lines; and shaded areas are 95\% credible regions. The numerical codes on each panel correspond to the U.S. Geological Survey gauge ID. 

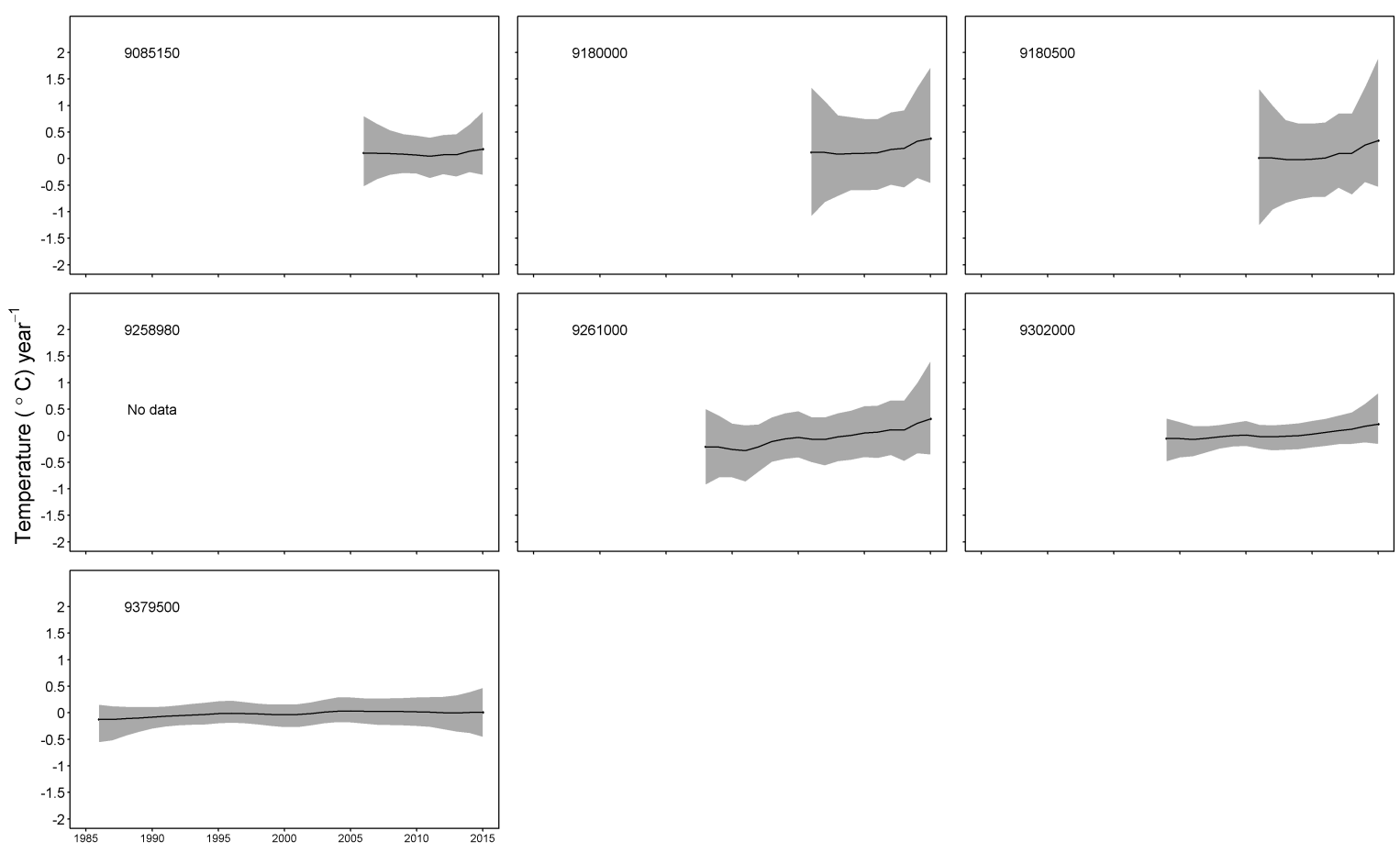

Year

Figure 6. Annual rates of change in winter river water temperature for sites located in the Upper Colorado River Basin (see Figure 1 for the site map). Solid lines are posterior means, and shaded areas are $95 \%$ credible regions. Numerical codes on each panel correspond to the U.S. Geological Survey gauge ID.
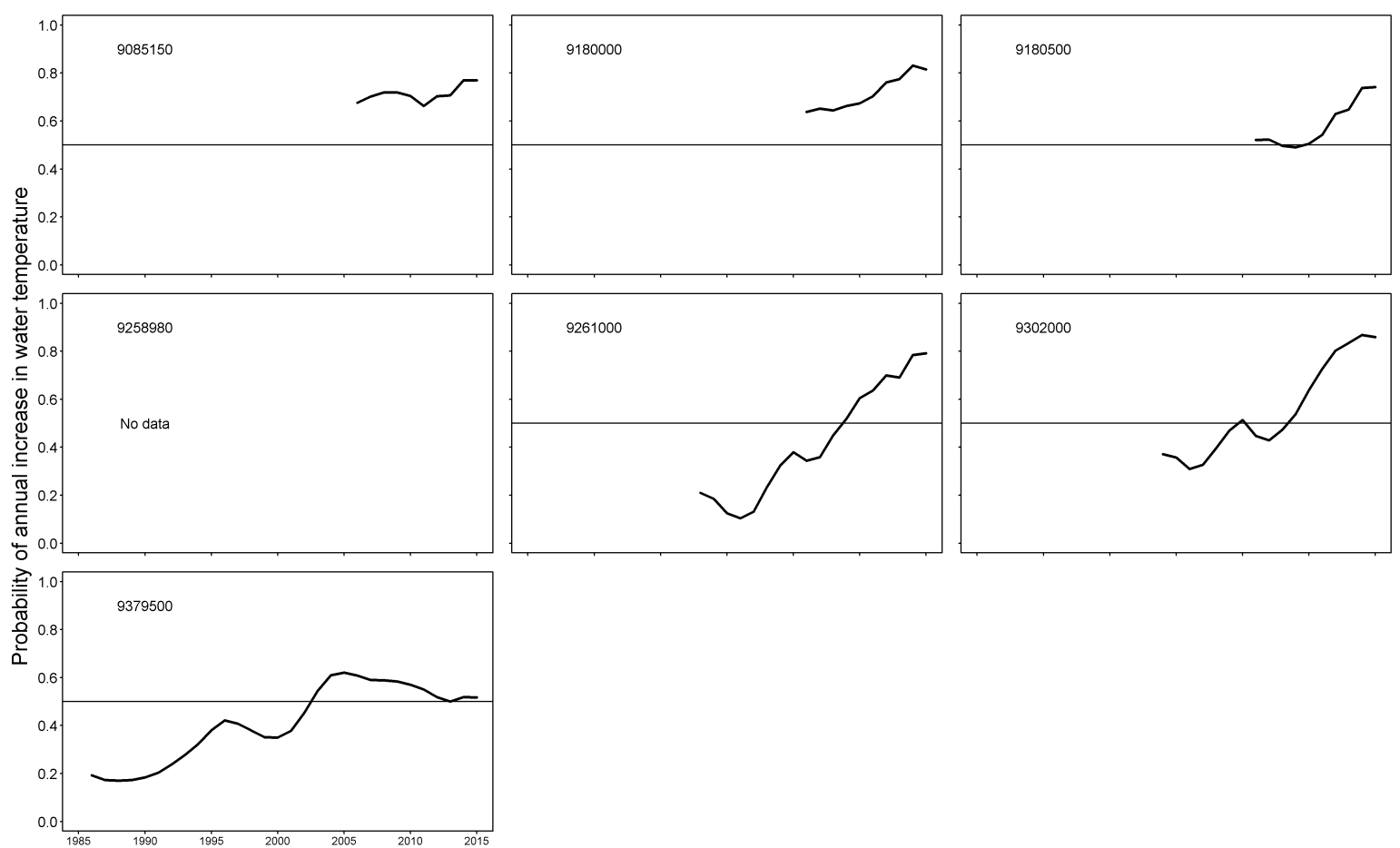

Year

Figure 7. Annual probabilities of an increase in winter river water temperature for sites located in the Upper Colorado River Basin (see Figure 1 for the site map). Numerical codes on each panel correspond to the U.S. Geological Survey gauge ID. 


\subsection{Land Use Correlations}

For river sites located in the eastern U.S., the average annual rate of change ranged from -0.24 to $0.06{ }^{\circ} \mathrm{C}$. Average annual rates of change range from -0.18 to $0.13{ }^{\circ} \mathrm{C}$ for sites located in the UCRB. For river sites located in the eastern U.S., average elevation, watershed area and urban land use were $250 \mathrm{~m}(\mathrm{SD}=168 \mathrm{~m}$; range $=0-515 \mathrm{~m}), 2033 \mathrm{~km}^{2}\left(\mathrm{SD}=4255 \mathrm{~km}^{2}\right.$; range $\left.=119-17,441 \mathrm{~km}^{2}\right)$ and $19 \%$ $(\mathrm{SD}=28 \%$, range $=0.0 \%-96 \%)$, respectively. For river sites located in the UCRB, average elevation, watershed area and urban land use for UCRB sites were 14,432 m (SD = $301 \mathrm{~m}$; range $=940-1903 \mathrm{~m})$, $59,924 \mathrm{~km}^{2}\left(\mathrm{SD}=84,667 \mathrm{~km}^{2}\right.$; range $\left.=2474-276,153 \mathrm{~km}^{2}\right)$ and $0.6 \%(\mathrm{SD}=0.6 \%$, range $=0.0 \%-2 \%)$, respectively. According to the regression tree analyses, no landscape predictors were identified as being related to the average annual rate of change for either region or for any season.

\section{Discussion}

Time series analysis of 17 river sites found little evidence of consistent seasonal increasing water temperature trends in the eastern U.S. In fact, most sites showed very little evidence of warming, based on estimated annual changes and associated uncertainty and calculated probabilities of annual increases of warming over the period of record. In contrast to the eastern U.S., we found more evidence of warming for river sites located in the UCRB, particularly during the fall and winter seasons. We did not find attributes of the landscape that were related to average annual changes (trends) in river water temperature for any season in either the eastern U.S. or the UCRB. However, land use and land cover have been shown to correlate with water temperature trends in other studies. For example, Rice and Jastram [18] found correlations between water temperature trends and agricultural land use and wetland cover in the mid-Atlantic region of the U.S. Although it is well established that natural landscape features (e.g., watershed area; [20]) and anthropogenic alterations to the landscape (e.g., urbanization; [31]) can influence river water temperatures, the lack of relationships to average trends in this study may be due to several factors. Two of the likely factors that limited the ability to find relationships, if they in fact exist, were (1) the relatively few number of sites in either region $(n=17$ in the eastern U.S. and $n=7$ for the UCRB) and (2) the limited range of values of landscape characteristics observed across our study sites. For example, the percentage of urban land use in the upstream catchment for UCRB sites ranged from $0 \%$ to $2 \%$, and although the percentage of urban land use ranged from $0 \%$ to $96 \%$ for the eastern U.S. sites, land use in these study sites was also predominately characterized by low urban land use (median percentage land use $=5 \%$ ).

\subsection{Effects on Fish and Fish Habitat}

Although little evidence was found for increasing river water temperature at most of the sites we examined, the highest probabilities of annual increases in river water temperature for UCRB sites occurred during the winter months. This could be important for fishes that have critical life-history requirements (e.g., gonadal development and spawning) that take place during these seasons and that are temperature dependent. These effects on thermal habitat conditions could also potentially affect critical life history events outside of the fall and winter months. For example, spring spawning fishes could spawn earlier with shorter, warmer winters [32]. In fact, it is increasingly recognized that understanding the seasonal variability in climate change effects may be important when attempting to understand current dynamics and for predicting effects under future scenarios, particularly in fish and wildlife populations [33]. For example, Kanno et al. [34] found that seasonal patterns in air temperature and precipitation, both of which are predicted to change under climate warming, were important drivers of survival and reproduction of eastern brook trout. In addition, Pease and Paukert [10] estimated that for each $1{ }^{\circ} \mathrm{C}$ increase in river water temperature, smallmouth bass Micropterus dolomieu consumption would increase by about $27 \%$, and growth would increase by about $6 \%$. Such changes in population vital rates could have consequences for entire riverine food webs. Although we summarized results as the probability of annual increases in water temperature, as 
previously stated, the results from the methods we present can easily be be summarized to calculate annual probabilities of water temperatures being equal to, greater or less than any temperature threshold that is relevant to conservation and management decision making.

\subsection{Comparison with Previous Research}

Our results highlight the utility of considering methods that allow for quantifying nonmonotonic trends in important fish habitat characteristics, such as water temperature. Our results, along with past studies, also illustrate the heterogeneity in river water temperature trends. Kaushal et al. [15] found that $44 \%$ (7/16 rivers) of river sites located in the eastern U.S. demonstrated statistically significant $(\alpha=0.05)$ long-term (linear) annual increases in water temperature, with a majority of rivers not changing statistically over the period of record. Even in the western U.S., where Kaushal et al. [15] found more rivers (9/16) with statistically-significant annual increases in water temperature, trends were not consistent among rivers, with many rivers showing no significant changes over time and one demonstrating a significant decline in average annual water temperature. Rice and Jastram [18] examined temporal trends in river water temperature across the Chesapeake Bay region, U.S., a region that overlaps considerably with our eastern U.S. region. Of the 129 sites Rice and Jastram [18] examined, 38\% (49/129) had significant long-term linear trends in temperature, with a median rate of change of $0.028^{\circ} \mathrm{C}$, and $6 \%(8 / 129)$ had significant decreasing trends in water temperature. Taken as a whole, this system heterogeneity has important implications for generalizing responses from a subset of rivers used in any given analysis to a region of interest.

Previous works modeling river temperatures over time have tended to use linear models, which are still able to detect changes, but these changes reflect long-term monotonic dynamics that might not capture meaningful smaller-scale dynamics or capture large changes that have occurred in recent time. In fact, it has been suggested that to effectively manage aquatic resources that management needs to adapt to changes in the physical environment [35]. The ability to adapt to changing conditions is greatly constrained when long-term average conditions are solely evaluated. Such methodological shortcomings serve to highlight the fact that a reliance on traditional regression methods that assume long-term linear trends may be inadequate for detecting changes in river water temperatures (or other habitat metrics) when non-monotonic dynamics are observed. Interestingly, for several of the UCRB sites (e.g., Gauge IDs 9180500, 9261000, and 930200), the observed increases in winter water temperature have occurred in recent years, with sites not showing long-term monotonic changes over the period of record. In fact, for these three river sites, fitting a linear regression model failed to find significant linear temporal trends in water temperature (linear regression estimates for: Gauge ID 9180500: trend estimate $\hat{\beta} \pm 1 \mathrm{SE}=0.061 \pm 0.12, p=0.62$; Gauge ID 9261000: $\hat{\beta}=-0.025 \pm 0.03, p=0.42$; Gauge ID 930200: $\hat{\beta}=0.020 \pm 0.02, p=0.41$ ). In turn, these traditional methods may not provide managers and decision makers with the necessary information to adapt to changing conditions. For example, because predictions from DLMs use more recent information and discount older information, they have been proven useful for making near-term predictions [36] that can be used to help inform decision making. The potential inadequacy of traditional statistical methods is also likely particularly important when attempting to detect trends in habitat conditions for sites with relatively short time series, since the statistical power of these traditional regression methods is partly dependent on the length of the time series (e.g., [18]). Use of time series models such as DLMs and related methods, as used in this study, circumvents these issues.

\section{Conclusions}

Quantifying temporal trends in important fish habitat attributes, such as water temperature, is important for understanding and predicting how fish populations and their habitat may respond to changing environmental conditions and management actions. Because many fish habitat metrics are affected by several often interacting natural and anthropogenic factors, the responses of habitat conditions and, therefore, fish populations will often exhibit nonlinear patterns [17,37]. As such, 
statistical methods that accommodate nonlinear dynamics are likely to provide more insight into the observed dynamics, providing managers with the information needed to adapt decision making to short-term changes in habitat conditions that may be necessary for managing aquatic resources in the face of a changing climate. Coupling DLMs with Bayesian estimation also provides the advantage of facilitating communication between managers and between managers and stakeholders by allowing for probabilistic statements about observed trends (e.g., the probability of an increasing (or decreasing) change over time), something that is not possible under a frequentist paradigm.

Supplementary Materials: The following are available online at www.mdpi.com/2073-4441/9/2/90/s1: Figures S1-S18.

Acknowledgments: Any use of trade, firm or product names is for descriptive purposes only and does not imply endorsement by the U.S. Government.

Author Contributions: Tyler Wagner conceived of and designed the analysis. Joanna B. Whittier and Jefferson T. DeWeber prepared the data. Stephen R. Midway and Craig P. Paukert helped with the study design. Tyler Wagner wrote the paper with assistance from Joanna B. Whittier, Jefferson T. DeWeber, Stephen R. Midway and Craig P. Paukert.

Conflicts of Interest: The authors declare no conflict of interest.

\section{References}

1. Demars, B.O.; Russell Manson, J.; Ólafsson, J.S.; Gíslason, G.M.; Gudmundsdóttir, R.; Woodward, G.; Reiss, J.; Pichler, D.E.; Rasmussen, J.J.; Friberg, N. Temperature and the metabolic balance of streams. Freshw. Biol. 2011, 56, 1106-1121.

2. Kitchell, J.F.; Stewart, D.J.; Weininger, D. Applications of a Bioenergetics Model to Yellow Perch (Perca flavescens) and Walleye (Stizostedion vitreum vitreum). J. Fish. Res. Board Can. 1977, 34, 1922-1935.

3. Magnuson, J.J.; Crowder, L.B.; Medvick, P.A. Temperature as an Ecological Resource. Am. Zool. 1979, 19, $331-343$.

4. Comte, L.; Grenouillet, G. Do stream fish track climate change? Assessing distribution shifts in recent decades. Ecography 2013, 36, 1236-1246.

5. Kennedy, R.J.; Crozier, W.W. Evidence of changing migratory patterns of wild Atlantic salmon Salmo salar smolts in the River Bush, Northern Ireland, and possible associations with climate change. J. Fish Biol. 2010, $76,1786-1805$.

6. Kovach, R.P.; Joyce, J.E.; Echave, J.D.; Lindberg, M.S.; Tallmon, D.A. Earlier Migration Timing, Decreasing Phenotypic Variation, and Biocomplexity in Multiple Salmonid Species. PLoS ONE 2013, 8, e53807.

7. Daufresne, M.; Boët, P. Climate change impacts on structure and diversity of fish communities in rivers. Glob. Chang. Biol. 2007, 13, 2467-2478.

8. Ficke, A.; Myrick, C.; Hansen, L. Potential impacts of global climate change on freshwater fisheries. Rev. Fish Biol. Fish. 2007, 17, 581-613.

9. Westhoff, J.T.; Paukert, C.P. Climate change simulations predict altered biotic response in a thermally heterogeneous stream system. PLOS ONE 2014, 9, e111438.

10. Pease, A.A.; Paukert, C.P. Potential impacts of climate change on growth and prey consumption of stream-dwelling smallmouth bass in the central United States. Ecol. Freshw. Fish 2014, 23, 336-346.

11. Jones, R.; Travers, C.; Rodgers, C.; Lazar, B.; English, E.; Lipton, J.; Vogel, J.; Strzepek, K.; Martinich, J. Climate change impacts on freshwater recreational fishing in the United States. Mitig. Adapt. Strateg. Glob. Chang. 2013, 18, 731-758.

12. Palmer, M.; Lettenmaier, D.; Poff.; Postel, S.; Richter, B.; Warner, R. Climate Change and River Ecosystems: Protection and Adaptation Options. Environ. Manag. 2009, 44, 1053-1068.

13. Mantua, N.; Tohver, I.; Hamlet, A. Climate change impacts on streamflow extremes and summertime stream temperature and their possible consequences for freshwater salmon habitat in Washington State. Clim. Chang. 2010, 102, 187-223.

14. Isaak, D.J.; Wollrab, S.; Horan, D.; Chandler, G. Climate change effects on stream and river temperatures across the northwest U.S. from 1980-2009 and implications for salmonid fishes. Clim. Chang. 2012, 113, 499-524.

15. Kaushal, S.S.; Likens, G.E.; Jaworski, N.A.; Pace, M.L.; Sides, A.M.; Seekell, D.; Belt, K.T.; Secor, D.H.; Wingate, R.L. Rising stream and river temperatures in the United States. Front. Ecol. Environ. 2010, 8, 461-466. 
16. Arismendi, I.; Johnson, S.L.; Dunham, J.B.; Haggerty, R.; Hockman-Wert, D. The paradox of cooling streams in a warming world: Regional climate trends do not parallel variable local trends in stream temperature in the Pacific continental United States. Geophys. Res. Lett. 2012, 39, L10401.

17. Orr, H.G.; Simpson, G.L.; des Clers, S.; Watts, G.; Hughes, M.; Hannaford, J.; Dunbar, M.J.; Laizé, C.L.R.; Wilby, R.L.; Battarbee, R.W.; et al. Detecting changing river temperatures in England and Wales. Hydrol. Process. 2015, 29, 752-766.

18. Rice, K.; Jastram, J. Rising air and stream-water temperatures in Chesapeake Bay region, USA. Clim. Chang. 2015, 128, 127-138.

19. Hudy, M.; Thieling, T.M.; Gillespie, N.; Smith, E.P. Distribution, status, and land use characteristics of subwatersheds within the native range of brook trout in the eastern United States. N. Am. J. Fish. Manag. 2008, 28, 1069-1085.

20. DeWeber, J.T.; Wagner, T. A regional neural network ensemble for predicting mean daily river water temperature. J. Hydrol. 2014, 517, 187-200.

21. DeWeber, J.T.; Wagner, T. Predicting brook trout occurrence in stream reaches throughout their native range in the eastern United States. Trans. Am. Fish. Soc. 2015, 144, 11-24.

22. Olden, J.D.; Poff, N.L.; Bestgen, K.R. Life-history strategies predict fish invasions and extirpations in the Colorado River Basin. Ecol. Monogr. 2006, 76, 25-40.

23. USEPA; USGS. National Hydrography Dataset Plus Version 1.0, NHDPlusV1; United States Environmental Protection Agency: Washington, DC, USA, 2005.

24. Sadraddini, S.; Azim, M.E.; Shimoda, Y.; Bhavsar, S.P.; Drouillard, K.G.; Backus, S.M.; Arhonditsis, G.B. A Bayesian assessment of the PCB temporal trends in Lake Erie fish communities. J. Gt. Lakes Res. 2011, 37, 507-520.

25. Lamon, C.L.; Carpenter, S.R.; Stow, C.A. Forecasting PCB concentrations in Lake Michigan salmonids: A dynamic linear model approach. Ecol. Appl. 1998, 8, 659-668.

26. Wagner, T.; Irwin, B.J.; Bence, J.R.; Hayes, D.B. Detecting temporal trends in freshwater fisheries surveys: Statistical power and the important linkages between management questions and monitoring objectives. Fisheries 2013, 38, 309-319.

27. Plummer, M. JAGS: A program for analysis of Bayesian graphical models using Gibbs sampling. In Proceedings of the 3rd International Workshop on Distributed Statistical Computing, Vienna, Austria, 20-22 March 2003.

28. R Core Team. R: A Language and Environment for Statistical Computing; R Foundation for Statistical Computing: Vienna, Austria, 2015.

29. Déath, G.; Fabricius, K.E. Classification and regression trees: A powerful yet simple technique for ecological data analysis. Ecology 2000, 81, 3178-3192.

30. Therneau, T.; Atkinson, B.; Ripley, B. rpart: Recursive Partitioning and Regression Trees, version 4.1-10; 2015. Available online: https://cran.r-project.org/web/packages/rpart/index.html (accessed on 3 February 2017).

31. Nelson, K.C.; Palmer, M.A. Stream temperature surges under urbanization and climate change: Data, models, and responses. JAWRA J. Am. Water Resour. Assoc. 2007, 43, 440-452.

32. Farmer, T.M.; Marschall, E.A.; Dabrowski, K.; Ludsin, S.A. Short winters threaten temperate fish populations. Nat. Commun. 2015, 6, 7724.

33. Shuter, B.J.; Finstad, A.G.; Helland, I.P.; Zweimüller, I.; Hölker, F. The role of winter phenology in shaping the ecology of freshwater fish and their sensitivities to climate change. Aquat. Sci. 2012, 74, 637-657.

34. Kanno, Y.; Letcher, B.H.; Hitt, N.P.; Boughton, D.A.; Wofford, J.E.B.; Zipkin, E.F. Seasonal weather patterns drive population vital rates and persistence in a stream fish. Glob. Chang. Biol. 2015, 21, 1856-1870.

35. Deyle, E.R.; Fogarty, M.; Hsieh, C.h.H.; Kaufman, L.; MacCall, A.D.; Munch, S.B.; Perretti, C.T.; Ye, H.; Sugihara, G. Predicting climate effects on Pacific sardine. Proc. Natl. Acad. Sci. USA 2013, 110, 6430-6435.

36. Lamon, E.C.; Stow, C.A. Lake Superior water level fluctuation and climatic factors: A dynamic linearmodel analysis. J. Gt. Lakes Res. 2010, 36, 172-178.

37. Brander, K. Climate and current anthropogenic impacts on fisheries. Clim. Chang. 2013, 119, 9-21.

(C) 2017 by the authors; licensee MDPI, Basel, Switzerland. This article is an open access article distributed under the terms and conditions of the Creative Commons Attribution (CC BY) license (http:/ / creativecommons.org/licenses/by/4.0/). 